\title{
COVID-19 related multisystem inflammatory syndrome in children (MIS-C): a case series from a tertiary care pediatric hospital in Qatar
}

Mohammad Rubayet Hasan ${ }^{1,2^{*}}$, Khaled Al Zubaidi ${ }^{1}$, Karim Diab ${ }^{1}$, Yahia Hejazi ${ }^{1}$, Sharon Bout-Tabaku ${ }^{1,2}$, Buthaina Al-Adba ${ }^{1}$, Eman Al Maslamani ${ }^{1}$, Mohammad Janahi ${ }^{1}$, Diane Roscoe ${ }^{1}$, Andres Perez Lopez ${ }^{1,2}$ and Patrick Tang ${ }^{1,2}$

\begin{abstract}
Background: Multisystem Inflammatory Syndrome in Children (MIS-C) is a severe complication of coronavirus disease 2019 (COVID-19) in children, which is increasingly being reported worldwide. Here we report the first case series of 7 children diagnosed with MIS-C in Qatar.

Methods: Clinical features and outcomes of COVID-19 positive patients admitted to Sidra Medicine, Qatar from June to October 2020, who met the WHO case definition for MIS-C were reviewed.

Results: The mean age in our case series was 5.6 years, of which $71.4 \%$ were males. All patients were previously healthy but had a history of COVID-19 infection. Fever, rash, vomiting and abdominal pain were the most common symptoms (70-100\%). The average hospitalization was 12.9 days with no case fatalities. Laboratory findings included lymphopenia and thrombocytopenia in most patients, as well as evidence of coagulopathy and elevated inflammatory markers such as C-reactive protein, ferritin and procalcitonin. Many patients (71.4\%) required inotropic support in intensive care, while only one required respiratory support. Although all patients had elevated cardiac biomarkers, cardiovascular involvement was observed in $42.9 \%$ of patients with one patient developing a giant coronary aneurysm. All patients received intravenous immunoglobulin (IVIG) and $86 \%$ of patients received corticosteroids, with two patients requiring treatment with IL-1 inhibitors.
\end{abstract}

Conclusions: Our report is one of the first reports on MIS-C from Asia. Although clinical features and outcomes are not significantly different from those reported elsewhere, lack of case fatalities in our cohort may indicate that early recognition and prompt medical attention is necessary for a favorable outcome in MIS-C.

Keywords: COVID-19, SARS-CoV-2, Multisystem inflammatory syndrome (MIS-C), Kawasaki disease

\footnotetext{
* Correspondence: mhasan@sidra.org

'Sidra Medicine, PO BOX 26999, Doha, Qatar

${ }^{2}$ Weill Cornell Medical College in Qatar, Doha, Qatar
}

(c) The Author(s). 2021 Open Access This article is licensed under a Creative Commons Attribution 4.0 International License, which permits use, sharing, adaptation, distribution and reproduction in any medium or format, as long as you give appropriate credit to the original author(s) and the source, provide a link to the Creative Commons licence, and indicate if changes were made. The images or other third party material in this article are included in the article's Creative Commons licence, unless indicated otherwise in a credit line to the material. If material is not included in the article's Creative Commons licence and your intended use is not permitted by statutory regulation or exceeds the permitted use, you will need to obtain permission directly from the copyright holder. To view a copy of this licence, visit http://creativecommons.org/licenses/by/4.0/. The Creative Commons Public Domain Dedication waiver (http://creativecommons.org/publicdomain/zero/1.0/) applies to the data made available in this article, unless otherwise stated in a credit line to the data. 


\section{Background}

The pandemic of coronavirus disease 2019 (COVID-19) caused by severe acute respiratory syndrome coronavirus 2 (SARS-CoV-2) has had a catastrophic effect on the human population with approximately $20 \%$ of infected persons experiencing severe or critical disease, and an overall case fatality rate of $2.3 \%$ [1]. Although most children with COVID-19 have mild symptoms or have no symptoms at all, some children become severely ill needing hospitalization, intensive care, or ventilatory support. Multisystem Inflammatory Syndrome in Children (MISC) is a rare but serious medical condition associated with COVID-19 [2]. MIS-C is defined by inflammation in different organs such as the heart, kidneys, lungs, brain, skin, eyes, or gastrointestinal system. The causes of MIS-C remain unknown but it has been associated with SARS-CoV-2 infection [3]. Approximately 40-50\% of children with MIS-C meet criteria for complete or incomplete Kawasaki disease (KD). The clinical presentation of MIS-C may also resemble that of toxic shock syndrome (TSS), secondary hemophagocytic lymphohistiocytosis, or macrophage activation syndrome (MAS) [4]. The true incidence of MIS-C is still uncertain but an estimated incidence of $0.6 \%$ among laboratory confirmed COVID-19 patients has been reported in New York [5].

To date, the majority of MIS-C cases have been reported from North America and European countries with very few reports from Asian countries [4-9]. Large case series conducted in the USA and UK show that risks associated with developing MIS-C may vary by gender, age and ethnicity. Although male gender and black and Hispanic races were predominantly affected [4-6], it is possible that MIS-C among Asians are underrepresented because of under reporting. In this study, we aim to review and summarize the clinical presentation, laboratory parameters, outcome and management of MIS-C cases presenting to a tertiary care pediatric hospital in Qatar and compare them with previously published cases in other countries.

\section{Methods}

Sidra Medicine is a 400-bed women's and children's tertiary care hospital in Qatar. MIS-C cases were identified by querying in the electronic medical record of children with COVID-19. Probable cases brought to the attention of infectious disease physicians and medical microbiologists were also included. Only patients who met the World Health Organization (WHO) case definition of MIS-C were selected for chart review. Data were recorded in a standardized form and deidentified. Descriptive statistics were performed and presented as mean and standard deviation $( \pm / S D)$ for continuous variables or as number and percentages for nominal/categorical variables.

\section{Results}

At the time of this report, there were approximately 138 , 000 COVID-19 cases and 237 associated deaths reported in Qatar. Since the initiation of COVID-19 screening at Sidra Medicine (April 16 to Nov. 21, 2020), a total of 28, 653 COVID-19 tests were performed of which 7812 were on individuals $<18$ years old. During this period, a total of 167 children were positive for COVID-19 by RT-qPCR, and 7 of these patients fulfilled the WHO criteria for MIS-C and were managed in our hospital. The mean age at diagnosis was $5.6 \pm 2.7$, and the majority of the cases were male (71.4\%) (Table 1). All patients were previously healthy. Five out of 7 cases were initially admitted to the pediatric intensive care unit (PICU), primarily for vascular support. All patients were managed according to the diagnostic and treatment algorithms established in May 2020 by a multidisciplinary group of pediatricians and subspecialists in Qatar, in response to COVID-19 pandemic and the emergence of MIS-C cases in Europe and the United States.

Fever and rash were the most common presenting symptoms among the MIS-C cases in our hospital with 100 and $85.7 \%$ of the patients experiencing these symptoms, respectively (Table 1). Additionally, gastrointestinal symptoms were common among these patients with 100, 71.4 and $42.9 \%$ patients presenting with vomiting, abdominal pain and loose stools, respectively. Upper respiratory tract infection (URTI) symptoms were less prevalent in our study group, with cough and sore throat experienced by one patient each, and conjunctivitis in 3 other patients. Two of the cases were suspected to have urinary tract infection (UTI) based on initial urine microscopy, however none had urinary tract symptoms at the time of presentation or had a positive urine culture after presentation.

Two of the cases had previous positive RT-qPCR results for SARS-CoV-2 (Table 2). At presentation, only one case had positive nasopharyngeal swab (NPS) for SARS-CoV-2. Two of the remaining 4 cases were initially negative by RT-qPCR in NPS but were later found to have positive COVID-19 serology. Additional RTqPCR testing for these patients using nasopharyngeal wash (NPW) specimens confirmed the presence of SARS-CoV-2 RNA. Of the 6 children who were tested for antibodies to SARS-CoV-2, all were positive.

All patients had extensive laboratory workup done upon admission or at the time when MISC was suspected (Table 2). Although total white blood cell (WBC) counts were variable among our study population with a range between 6.9 to $27.3\left(10^{9} / \mathrm{L}\right), 5$ of 7 cases were lymphopenic for their age. Additionally, 5 cases had a low platelet count for their age, although none had severe thrombocytopenia. All of our MIS-C cases showed a hyperinflammatory status with remarkably high $\mathrm{C}$ - 
Table 1 Patient characteristics and clinical presentation

\begin{tabular}{|c|c|c|c|c|c|c|c|c|}
\hline & Case-1 & Case-2 & Case-3 & Case-4 & Case-5 & Case-6 & Case-7 & Summary \\
\hline \multicolumn{9}{|l|}{ Demographics } \\
\hline Age & 6 & 6 & 3 & 7 & 7 & 9 & 1 & Mean, $5.6 \pm 2.7$ \\
\hline Gender & Male & Male & Male & Male & Female & Female & Male & Male, $71.4 \%$ \\
\hline \multicolumn{9}{|l|}{ Clinical presentation } \\
\hline Fever & Yes & Yes & Yes & Yes & Yes & Yes & Yes & $100 \%$ \\
\hline Rash & No & Yes & Yes & Yes & Yes & Yes & Yes & $85.7 \%$ \\
\hline Tachycardia & Yes & No & Yes & Yes & No & Yes & Yes & $71.4 \%$ \\
\hline Tachypnea & No & Yes & No & No & Yes & No & No & $28.6 \%$ \\
\hline Hypotension & Yes & Yes & No & Yes & No & No & No & $42.9 \%$ \\
\hline Abdominal pain & Yes & No & Yes & ${ }^{\mathrm{a}}$ Yes & Yes & Yes & No & $71.4 \%$ \\
\hline Diarrhea & No & No & Yes & No & No & Yes & Yes & $42.9 \%$ \\
\hline Vomiting & Yes & Yes & Yes & Yes & Yes & Yes & Yes & $100 \%$ \\
\hline Decreased oral intake & Yes & Yes & Yes & No & No & No & Yes & $57.1 \%$ \\
\hline Cough & Yes & No & No & No & No & No & No & $14.3 \%$ \\
\hline Sore throat & No & Yes & No & No & No & No & No & $14.3 \%$ \\
\hline Conjunctivitis & No & Yes & No & Yes & No & Yes & Yes & $57.1 \%$ \\
\hline
\end{tabular}

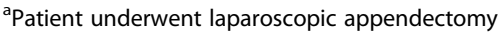

reactive protein $(\mathrm{CRP})$, procalcitonin $(\mathrm{PCT})$ and ferritin levels, and deranged coagulation profile. IL- 6 was high in 3 of 4 cases who were tested during their hospital stay.

Chest radiography was performed on 6 of 7 patients (Table 3). The most commonly described abnormalities were bilateral perihilar infiltrates and peribronchial thickening. Bilateral interstitial opacities and pulmonary edema were described in just one patient. Abdominal ultrasound (US) was performed on 6 of 7 patients. The most significant finding was that of an aortic aneurysm in one patient. The remaining patients had a variety of non-specific findings including increased echogenicity of the liver, gall bladder wall edema and thickening, bulky and echogenic kidneys, enlarged mesenteric lymph nodes, pleural effusions and ascites.

Echocardiograms were performed on all patients at diagnosis with at least 4 weeks of follow-up, and after 8 weeks or earlier for patients with abnormal findings (Table 3). Cardiovascular involvement was seen in 3 of 7 patients in our study group (42.9\%). Two patients had transient ventricular dysfunction with ejection fraction $(\mathrm{EF})<55 \%$. Five patients $(71.4 \%)$ received vasoactive support. All patients had elevated levels of N-terminal B-type natriuretic peptide (NT-proBNP) and troponin (Table 2). None of our cases had arrhythmias even in the acute stage. Coronary-artery aneurysm was identified on the basis of a $\mathrm{z}$ score of 2.5 or higher in the left anterior descending (LAD) or right coronary artery (RCA) in one patient (Table 3; Case-7) who developed a giant aneurysm in the left anterior descending (LAD) coronary artery (initially $4.9 \mathrm{~mm}, \mathrm{z}$-score $>10$ ). This patient also had a dilated left main coronary artery measuring $3.9 \mathrm{~mm}$ (z-score +3.7$)$ and a dilated right coronary artery measuring $2.6 \mathrm{~mm}$ (z-score + 2.7) (Fig. 1, Supplemental video). The patient was placed on anticoagulation and dual antiplatelet therapy in addition to two doses of intravenous immunoglobulin (IVIG) and interleukin-1 (IL-1) inhibitor (anakinra). His LAD aneurysm enlarged to $9.5 \mathrm{~mm} \mathrm{(z-}$ score +31.4$)$ and was still present on the latest follow-up after 8 weeks from diagnosis.

The mean hospital stay of our MIS-C patients was 12.9 days, with 5 initially requiring intensive care management for ionotropic support (Table 3). Only one case (Case-4; Table 3) presented with acute respiratory distress syndrome (ARDS) and required mechanical ventilation. This patient also had prolonged fever and required 2 doses of IVIG, pulse steroids, and anakinra after no response to the initial measures. Broad spectrum antibiotics were initiated in all of the cases after consultation with the infectious disease team (Table 4). Patient 1 initially received cefepime and vancomycin for suspected urosepsis, but his treatment was later upgraded to meropenem and vancomycin due to a lack of response. Antibiotic treatment was de-escalated after all culture results were negative and the patient was tested positive for COVID-19. Patient 3 received ceftriaxone and metronidazole as post-appendectomy prophylactic treatment. All other patients received antibiotics for suspected infection while waiting for culture results. Aspirin was given to all patients during their hospital stay and on discharge for coronary thrombosis prophylaxis. All of 
Table 2 Laboratory results

\begin{tabular}{|c|c|c|c|c|c|c|c|c|}
\hline & Case-1 & Case-2 & Case-3 & Case-4 & Case-5 & Case-6 & Case-7 & Summary \\
\hline \multicolumn{9}{|l|}{ COVID-19 } \\
\hline RT-qPCR & $\begin{array}{l}\text { NPS-Neg } \\
\text { NPW-Pos }\end{array}$ & $\begin{array}{l}\text { NPS-Neg } \\
\text { NPW-PoS }\end{array}$ & NPS-Pos & NPS-Neg & ${ }^{\mathrm{a}}$ NPS-Pos & ${ }^{a}$ NPS-Pos & NPS-Neg & $\begin{array}{l}71.4 \% \text { cases positive in } \\
\text { at least one specimen }\end{array}$ \\
\hline Serology & Positive & Positive & Positive & Positive & Not done & Positive & Positive & $6 / 6,100 \%$ positive \\
\hline \multicolumn{9}{|l|}{ Hematology } \\
\hline WBC $\left(10^{9} / \mathrm{L}\right)$ & 27.3 & 19.4 & 16 & 9.7 & 16.9 & 6.9 & 24.1 & $\begin{array}{l}71.4 \% \text { above range } \\
\text { (Ref: } 4-14 \text { ) }\end{array}$ \\
\hline Neutrophil $\left(10^{9} / \mathrm{L}\right)$ & 24.4 & 16.5 & 5.3 & 9.5 & 13.9 & 4.6 & 16.1 & $\begin{array}{l}71.4 \% \text { above range } \\
\text { (Ref: } 0.8-7.2 \text { ) }\end{array}$ \\
\hline Lymphocyte $\left(10^{9} / \mathrm{L}\right)$ & 0.9 & 0.8 & 1.2 & 0.2 & 2.1 & 0.6 & 6.5 & $\begin{array}{l}\text { 71.4\% below range } \\
\text { (Ref: } 1.3-8 \text { ) }\end{array}$ \\
\hline Platelets $\left(10^{3} / \mathrm{mL}\right)$ & 140 & 80 & 570 & 105 & 116 & 105 & 900 & $\begin{array}{l}\text { 71.4\% below range } \\
\text { (Ref: } 150-400 \text { ) }\end{array}$ \\
\hline \multicolumn{9}{|l|}{ Inflammatory markers } \\
\hline CRP (mg/L) & 262.2 & 228.3 & 162 & 304.5 & 93 & 82.8 & 143 & $\begin{array}{l}100 \% \text { above range } \\
\text { (Ref: } 0-7.5 \text { ) }\end{array}$ \\
\hline Ferritin $(\mathrm{ng} / \mathrm{mL})$ & 324 & 581 & 377 & 334 & 326 & 341 & 621 & $\begin{array}{l}\text { 100\% above range } \\
\text { (Ref: } 10-56 \text { ) }\end{array}$ \\
\hline PCT (ng/mL) & 21.6 & 7.22 & 9.4 & $>50$ & 2.15 & Not done & 0.59 & $\begin{array}{l}6 / 6,100 \% \text { above range } \\
\text { (Ref: }<0.1 \text { ) }\end{array}$ \\
\hline IL-6 (pg/mL) & 35 & 4 & Not done & Not done & 2665 & Not done & 100 & $\begin{array}{l}\text { 3/4 above range } \\
\text { (Ref: } 0-16.4 \text { ) }\end{array}$ \\
\hline \multicolumn{9}{|l|}{ Coagulation } \\
\hline PT (sec) & 16.8 & 15.1 & 18.3 & 17 & 17.5 & 15.9 & 12 & $\begin{array}{l}\text { 83\% above range } \\
\text { (Ref: } 11.7-15.1 \text { ) }\end{array}$ \\
\hline D-dimer (mg/L) & 7440 & 2266 & 7500 & $>7500$ & 3538 & 2381 & 3060 & $\begin{array}{l}\text { 100\% above range } \\
\text { (Ref: } \leq 500 \text { ) }\end{array}$ \\
\hline Fibrinogen (mg/dL) & 4 & 3.9 & 3.4 & 4.4 & 3.7 & 3.6 & 4.3 & $\begin{array}{l}\text { 28.6\% above range } \\
\text { (Ref: } 1.6-4 \text { ) }\end{array}$ \\
\hline \multicolumn{9}{|l|}{ Cardiac } \\
\hline Troponin (ng/L) & 40 & 14 & 68 & 309 & 161 & 34 & 4 & $\begin{array}{l}\text { 100\% above range } \\
\text { (Ref: } 0-0.4 \text { ) }\end{array}$ \\
\hline NT-proBNP (ng/L) & 5253 & 7006 & 2314 & 2874 & 592 & 506 & 1444 & $\begin{array}{l}\text { 100\% above range } \\
\text { (Ref: < 125) }\end{array}$ \\
\hline
\end{tabular}

NPS nasopharyngeal swab; NPW nasopharyngeal wash; WBC white blood cell; CRP C-reactive protein; PCT procalcitonin; PT prothrombin time; NT-proBNP Nterminal B-type natriuretic peptide

${ }^{\text {a }}$ Previous positive

our patients recovered and were discharged from the hospital in good clinical condition.

\section{Discussion}

This case series describes 7 cases of MIS-C in our hospital. Similar to earlier reports, all patients were previously healthy and presented at our hospital approximately 4-6 weeks after the peak of the COVID-19 outbreak in the country [4]. In most cases, MIS-C was suspected early because of a history of COVID-19 infection based on RT-qPCR or serology. In two cases who were initially negative by PCR, antibody testing was useful to determine the COVID-19 infection status of the suspected MIS-C patients. Overall, 71.4\% of our patients had positive COVID-19 PCR results as compared to
$50 \%$ of positive COVID-19 PCR results reported in other studies $[10,11]$. The fact that all patients in our case series who were tested for SARS-CoV-2 antibody were positive at the time of presentation supports the postinfectious nature of the disease [12].

The clinical presentations of MIS-C patients in this case series were mostly similar to earlier reports with fever and gastrointestinal problems being the most common initial symptoms. [11, 13] In our experience, abdominal pain in these patients was severe in nature and resembled appendicitis. In fact, one of our patients underwent appendectomy, which subsequently showed a normal appendix. Respiratory symptoms were less prominent in our cohort with only one case having cough and another being intubated as part of ionotropic support 
Table 3 Clinical outcome

\begin{tabular}{|c|c|c|c|c|c|c|c|c|}
\hline & Case-1 & Case-2 & Case-3 & Case-4 & Case-5 & Case-6 & Case-7 & Summary \\
\hline $\begin{array}{l}\text { Hospital length of stay } \\
\text { (days) }\end{array}$ & 12 & 10 & 6 & 20 & 7 & 8 & 27 & Mean, $12.9 \pm 7.8$ \\
\hline ICU stay (days) & 12 & 10 & None & 11 & 4 & 3 & None & $71.4 \%$ \\
\hline Shock & Yes & Yes & None & Yes & None & Yes & None & $57.1 \%$ \\
\hline Abnormal echocardiogram & Yes & No & No & No & Yes & No & Yes & $42.9 \%$ \\
\hline Abnormal EKG & $\begin{array}{l}\text { Low voltage } \\
\text { in limb leads }\end{array}$ & $\begin{array}{l}\text { Not } \\
\text { done }\end{array}$ & $\begin{array}{l}\text { Not } \\
\text { done }\end{array}$ & $\begin{array}{l}\text { Initial ECG } \\
\text { RBBB }\end{array}$ & No & No & $\begin{array}{l}\text { Deep Q wave } \\
\text { in inferior leads }\end{array}$ & $42.9 \%$ \\
\hline LAD/RCA z-score $\geq 2.5$ & No & No & No & No & No & No & ${ }^{a}$ Yes & $14.3 \%$ \\
\hline Pericardial Effusion & Minimal & No & No & No & No & No & No & $14.3 \%$ \\
\hline Ejection Fraction & $51 \%$ & $65 \%$ & $68 \%$ & $65 \%$ & $54 \%$ & $69 \%$ & $70 \%$ & $\begin{array}{l}28.6 \% \text { below range } \\
\text { (Ref: < 55\%) }\end{array}$ \\
\hline Mitral valve regurgitation & Mild & No & Trivial & No & Mild & No & No & $42.9 \%$ \\
\hline Abnormal CXR & Yes & Yes & Yes & Yes & Yes & $\begin{array}{l}\text { Not } \\
\text { done }\end{array}$ & Yes & $\begin{array}{l}6 / 6,100 \% \\
\text { abnormal }\end{array}$ \\
\hline Pleural effusion & $\begin{array}{l}\text { Small } \\
\text { bilateral }\end{array}$ & No & No & No & $\begin{array}{l}\text { Small right } \\
\text { sided }\end{array}$ & No & No & $28.6 \%$ \\
\hline Mechanical ventilation & None & None & None & Yes & None & None & None & $14.3 \%$ \\
\hline Abnormal US abdomen & Yes & Yes & Yes & No & Yes & $\begin{array}{l}\text { Not } \\
\text { done }\end{array}$ & Yes & $\begin{array}{l}5 / 6,83.3 \% \\
\text { abnormal }\end{array}$ \\
\hline
\end{tabular}

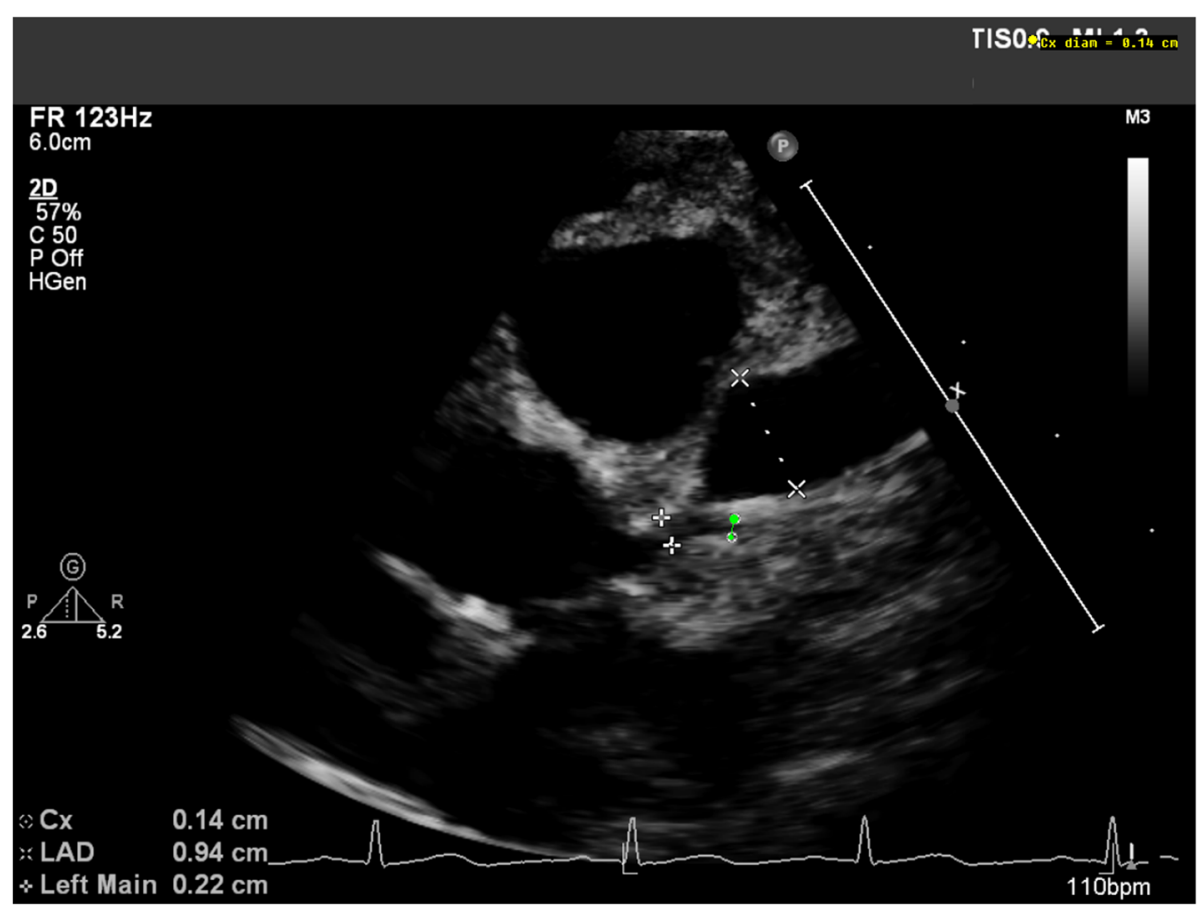

Fig. 1 Coronary artery aneurysm in a MIS-C patient (Case 7). Echocardiographic short axis view of the left coronary artery system showing the mildly dilated main left coronary artery and the giant aneurysm in the left anterior descending coronary artery with the respective measurements (Video in the supplemental file). LMCA: Left Main Coronary Artery; Cx: circumflex; LAD: Left Anterior Descending 


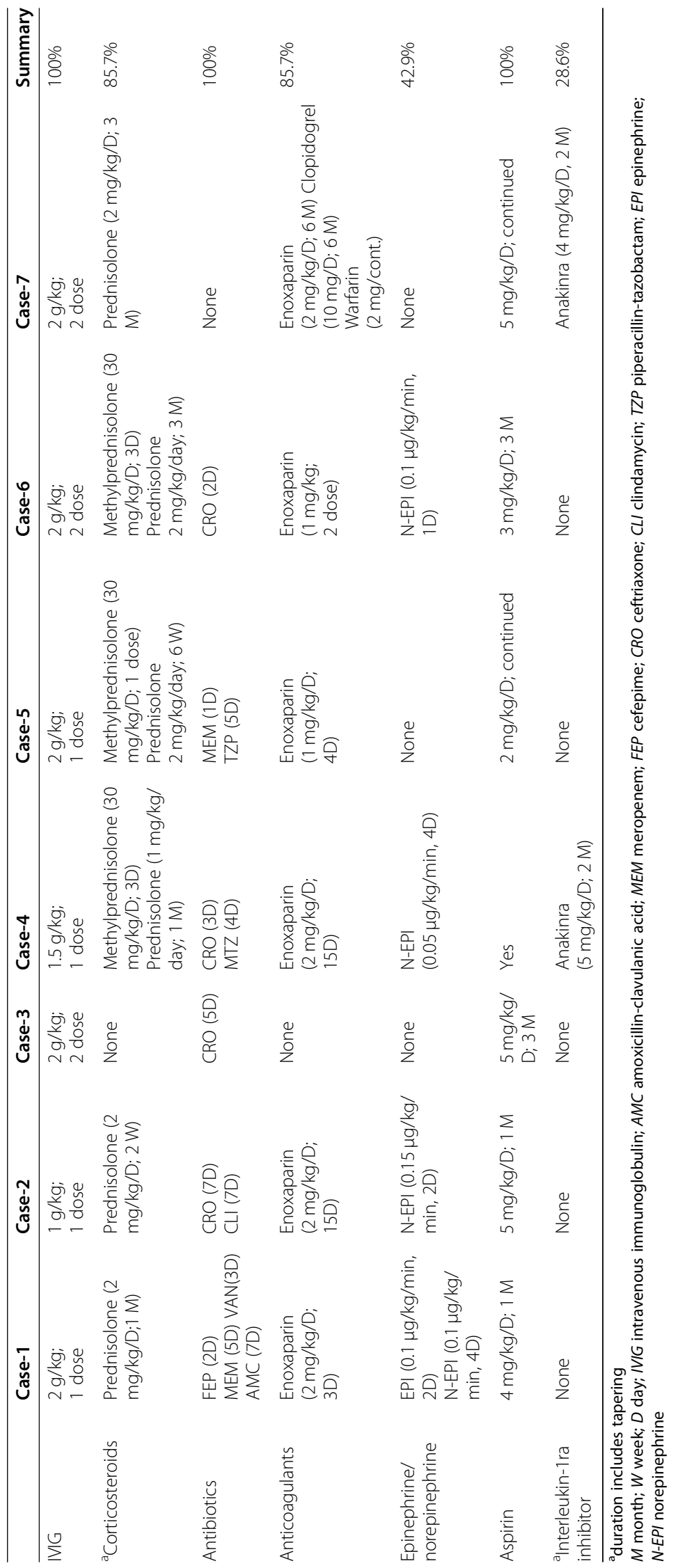


without significant lung pathology. This is consistent with previous studies although some studies have reported a higher percentage of cases requiring respiratory support during their illness $[10,13,14]$. The signs and symptoms of patients in our case series differed from a recently published study on Latin American children which showed higher rates of upper and lower respiratory tract infections and a lower percentage of gastrointestinal symptoms among the MIS-C patients [15].

Significant cardiac involvement in cases of MIS-C has been documented in recent reports highlighting the common similarity with KD. This emphasizes the need for cardiac evaluation with echocardiography at diagnosis and at regular intervals consistent with the management of $\mathrm{KD}[4,16]$. It is reported that up to $56 \%$ of cases can have decreased systolic ventricular function with $\mathrm{EF}<55 \%$, the most common cardiac abnormality seen in these patients $[13,16]$, which in contrast to KD has less propensity for significant ventricular dysfunction [14]. In our small case series, although approximately three quarter of patients required vasopressor support, only two had transient LV dysfunction that recovered within a short period, which is in contrast with patients with KD who rarely present with hemodynamic instability [4].

Elevated troponin levels have been previously associated with poor outcome in patients with COVID-19 and could be a reflection of the degree of systemic inflammation and myocardial effects [17]. Elevated troponin, NTproBNP and D-dimer levels were also commonly noted in our case series (Table 2). Of particular interest is the degree of coronary artery involvement in MIS-C cases which occurred in one case with the patient developing a giant aneurysm in the LAD and dilatation of both the left main and right coronary arteries. Coronary artery involvement in MIS-C cases is reported to occur in up to $15 \%$ of cases in a recent report with few patients developing giant aneurysms. [11, 14, 16, 18] Although the true incidence of such involvement is still to be defined, it seems similar to that in KD where it occurs in about 25 and $4 \%$ of untreated and treated patients, respectively [19]. In addition, no clear predisposing factors were identified for those with higher risk for development of coronary involvement in MIS-C cases.

Although the pathophysiology of MIS-C is poorly understood, it has been suggested that it is a postinfectious process triggered by an abnormal immunophenotype that is distinct from KD, MAS, and cytokine release syndrome [2]. Elevated inflammatory markers and evidence of coagulopathy are common laboratory findings and are among the most important criteria for the clinical diagnosis of MIS-C. However, the correlation between the two in MIS-C patients is not known. It has been suggested that 'cytokine storm' or the enhanced production of inflammatory cytokines, especially IL-6, may lead to the activation of the coagulation cascade in COVID-19 patients [20, 21]. In our study, coagulation dysfunction in MIS-C patients was seen in terms of markedly elevated D-dimer and abnormal PT. However, fibrinogen levels were slightly elevated in only 2 patients and IL-6 levels were not available for all patients. Therefore, the role of IL-6 or any other inflammatory cytokines remained inconclusive in our study, but notably, one patient (case 5) who had exceptionally high level of IL-6 did not have proportionally higher levels of coagulation markers. This is in contrast to the findings of a study which showed a positive correlation between IL-6 level and fibrinogen level in patients with COVID-19 associated ARDS [22]. Other studies suggest that the cytokine storm in MIS-C patients differs from those in severe acute COVID-19 and hypothesize the role of autoantibodies such as lupus anticoagulants in COVID19 associated coagulopathy and thrombosis [23-25].

Previous studies showed a death rate of $1.7-1.8 \%$ [13, 26]. Fortunately, all of the cases in our case series had a favorable outcome, with no deaths. All patients received aspirin for coronary thrombosis prophylaxis and one patient with giant aneurysm was placed on dual antiplatelet therapy according to American Heart Association (AHA) guidelines for treating patients with Kawasaki disease [19]. It was also noteworthy that all 7 patients except one were initially treated with antibiotics. Although there is a great concern about the overuse of antibiotics in children with COVID-19 [27], it should be pointed out that the substantial overlap between the clinical presentation of MIS-C and other life-threatening bacterial infections such as sepsis and toxic shock syndrome, likely justify the empirical use of broad-spectrum antibiotics in these patients until a diagnosis is established and negative culture results are available [28]. Biomarkers that accurately rule out bacterial infections in patients with an equivocal clinical presentation could reduce antibiotic exposure in patients with MIS-C.

With the exception of two cases, all patients in our case series initially required PICU care with inotropic support being the main reason for PICU admission, consistent with previous reports of MIS-C $[4,10,13,29]$. The majority of our cases responded well to IVIG with or without intravenous (IV) corticosteroids in terms of subsidence of fever and decreased need for inotropic support. Only two cases required two doses of IVIG and IL-1 inhibitor, as these patients had a more complicated course with ARDS and coronary aneurysm, respectively. These patients also had prolonged fever, which did not respond to initial measures. A similar pattern in clinical response was noted in less than $10 \%$ of cases requiring IL-1 or IL-6 antagonists in a recent systematic review [13]. Due to the similarities between MIS-C and KD and 
their cardiac involvement, current treatment strategies are similar from cardiac point of view [4, 13]. However, the long-term outcomes of MIS-C, such as the sequelae of coronary artery aneurysm formation, remain unknown. The benefit of longer-term cardiac follow up to evaluate the effects on cardiac function and persistence or regression of coronary aneurysms remain to be determined.

\section{Conclusions}

We report the first case series of COVID-19 associated MIS-C in Qatar. Our patients commonly presented with fever, rash and gastrointestinal symptoms and required intensive care. Most common laboratory findings include lymphopenia and thrombocytopenia and elevated CRP, ferritin, PCT, D-dimers, PT, NT-proBNP and troponin. Only one patient had acute respiratory distress syndrome (ARDS) and required respiratory support, and cardiovascular involvement was observed in approximately $43 \%$ of patients, with one patient with coronaryartery aneurysms. All patients were treated with IVIG, and some received corticosteroids and IL-1 inhibitors; all patients were fully recovered.

\begin{abstract}
Abbreviations
COVID-19: Coronavirus disease 2019; MIS-C: Multisystem inflammatory syndrome in children; WHO: World Health Organization; L-1: Interleukin - 1; SARS-CoV-2: Severe acute respiratory syndrome coronavirus 2; KD: Kawasaki disease; RT-qPCR: Reverse transcriptase - quantitative real time polymerase chain reaction; PICU: Pediatric intensive care unit; URTI: Upper respiratory tract infection; UTI: Urinary tract infection; NPW: Nasopharyngeal wash; WBC: White blood cell; CRP: C-reactive protein; PCT: Procalcitonin; IL6: Interleukin - 6; US: Ultrasound; EF: Ejection fraction; NT-proBNP: N-terminal B-type natriuretic peptide; LAD: Left anterior descending; RCA: Right coronary artery; ARDS: Acute respiratory distress syndrome; IVIG: Intravenous immunoglobulin; IV: Intravenous
\end{abstract}

\section{Supplementary Information}

The online version contains supplementary material available at https://doi. org/10.1186/s12887-021-02743-8.

Additional file 1. Coronary artery aneurysm in a MIS-C patient. Video of echocardiogram performed on a MIS-C patient with coronary artery aneurysm.

\section{Acknowledgments}

The authors thank all staff members in Sidra Medicine, Qatar who were involved in the clinical care of the subjects of the study.

\section{Authors' contributions}

M.R.H. conceptualized and designed the study and performed data analysis M.R.H., K.A.Z., K.D., and Y.H. reviewed patient charts and collected data. M.R.H., K.A.Z., K.D. A.P.L. and S.B.T. drafted the manuscript. B.A.A., E.A.A., M.J., D.R., and P.T. participated in the critical review of the final manuscript. The author(s) read and approved the final manuscript.

\section{Funding}

No funding was received for this study.

\section{Availability of data and materials}

All data generated or analysed during this study are included in this published article [and its supplementary information files].

\section{Declarations}

Ethics approval and consent to participate

Ethics approval for the study and a waiver of informed consent was obtained from the Institutional Review Board of Sidra Medicine. All methods were carried out in accordance with relevant guidelines and regulations.

\section{Consent for publication}

Not applicable.

\section{Competing interests}

The authors declare that they have no competing interests.

Received: 9 December 2020 Accepted: 24 May 2021

Published online: 08 June 2021

\section{References}

1. Coronavirus disease 2019 (COVID-19): Clinical features [https://www.uptoda te.com/contents/coronavirus-disease-2019-covid-19-clinical-fea tures?topicRef $=126981 \&$ source $=$ see_link].

2. Coronavirus disease 2019 (COVID-19): Multisystem inflammatory syndrome in children (MIS-C) clinical features, evaluation, and diagnosis [https://www. uptodate.com/contents/coronavirus-disease-2019-covid-19-multisystem-infla mmatory-syndrome-in-children-mis-c-clinical-features-evaluation-and-dia gnosis?topicRef=129614\&source=see_link].

3. Multisystem Inflammatory Syndrome (MIS-C) [https://www.cdc.gov/corona virus/2019-ncov/daily-life-coping/children/mis-c.html].

4. Feldstein LR, Rose EB, Horwitz SM, Collins JP, Newhams MM, Son MBF, et al. Multisystem inflammatory syndrome in U.S. children and adolescents. N Engl J Med. 2020;383(4):334-46. https://doi.org/10.1056/NEJMoa2021680.

5. Dufort EM, Koumans EH, Chow EJ, Rosenthal EM, Muse A, Rowlands J, et al. Multisystem inflammatory syndrome in children in New York state. N Engl J Med. 2020;383(4):347-58. https://doi.org/10.1056/NEJMoa2021756.

6. Davies P, Evans C, Kanthimathinathan HK, Lillie J, Brierley J, Waters G, et al. Intensive care admissions of children with paediatric inflammatory multisystem syndrome temporally associated with SARS-CoV-2 (PIMS-TS) in the UK: a multicentre observational study. Lancet Child Adolesc Health. 2020;4(9):669-77. https://doi.org/10.1016/S2352-4642(20)30215-7.

7. Mamishi S, Movahedi Z, Mohammadi M, Ziaee V, Khodabandeh M, Abdolsalehi MR, et al. Multisystem inflammatory syndrome associated with SARS-CoV-2 infection in 45 children: a first report from Iran. Epidemiol Infect. 2020;148:e196. https://doi.org/10.1017/S095026882000196X.

8. Al Ameer HH, AlKadhem SM, Busaleh F, AlKhwaitm S, Llaguno MBB. Multisystem inflammatory syndrome in children temporally related to COVID-19: a case report from Saudi Arabia. Cureus. 2020;12(9):e10589. https://doi.org/10.7759/cureus.10589.

9. Almoosa ZA, Al Ameer HH, AlKadhem SM, Busaleh F, AlMuhanna FA, Kattih O. Multisystem inflammatory syndrome in children, the real disease of COVID-19 in pediatrics - a multicenter case series from Al-Ahsa, Saudi Arabia. Cureus. 2020;12(10):e11064. https://doi.org/10.7759/cureus.11064.

10. Torres JP, Izquierdo G, Acuna M, Pavez D, Reyes F, Fritis A, et al. Multisystem inflammatory syndrome in children (MIS-C): report of the clinical and epidemiological characteristics of cases in Santiago de Chile during the SARS-CoV-2 pandemic. Int J Infect Dis. 2020;100:75-81. https://doi.org/10.1 016/j.ijid.2020.08.062.

11. Kaushik A, Gupta S, Sood M, Sharma S, Verma S. A systematic review of multisystem inflammatory syndrome in children associated with SARS-CoV-2 infection. Pediatr Infect Dis J. 2020;39(11):e340-6. https://doi.org/10.1097/ INF.0000000000002888.

12. Buonsenso D, Riitano F, Valentini P. Pediatric inflammatory multisystem syndrome temporally related with SARS-CoV-2: immunological similarities with acute rheumatic fever and toxic shock syndrome. Front Pediatr. 2020;8: 574. https://doi.org/10.3389/fped.2020.00574.

13. Ahmed M, Advani S, Moreira A, Zoretic S, Martinez J, Chorath K, et al. Multisystem inflammatory syndrome in children: a systematic review. EClinicalMedicine. 2020;26:100527. https://doi.org/10.1016/j.eclinm.2020.1 00527.

14. Whittaker E, Bamford A, Kenny J, Kaforou M, Jones CE, Shah P, et al. Clinical characteristics of 58 children with a pediatric inflammatory multisystem syndrome temporally associated with SARS-CoV-2. JAMA. 2020:324(3):25969. https://doi.org/10.1001/jama.2020.10369. 
15. Antunez-Montes OY, Escamilla MI, Figueroa-Uribe AF, Arteaga-Menchaca E, Lavariega-Sarachaga M, Salcedo-Lozada P, et al. COVID-19 and multisystem inflammatory syndrome in Latin American children: a multinational study. Pediatr Infect Dis J. 2021;40(1):e1-6. https://doi.org/10.1097/INF. 0000000000002949.

16. Loke $\mathrm{YH}$, Berul $\mathrm{Cl}$, Harahsheh AS. Multisystem inflammatory syndrome in children: is there a linkage to Kawasaki disease? Trends Cardiovasc Med. 2020;30(7):389-96. https://doi.org/10.1016/j.tcm.2020.07.004.

17. Nguyen Y, Corre F, Honsel V, Curac S, Zarrouk V, Burtz CP, et al. A nomogram to predict the risk of unfavourable outcome in COVID-19: a retrospective cohort of 279 hospitalized patients in Paris area. Ann Med. 2020;52(7):367-75. https://doi.org/10.1080/07853890.2020.1803499.

18. Cheung EW, Zachariah P, Gorelik M, Boneparth A, Kernie SG, Orange JS, et al. Multisystem inflammatory syndrome related to COVID-19 in previously healthy children and adolescents in new York City. JAMA. 2020;324(3):294-6. https://doi.org/10.1001/jama.2020.10374.

19. McCrindle BW, Rowley AH, Newburger JW, Burns JC, Bolger AF, Gewitz M, et al. Diagnosis, treatment, and long-term Management of Kawasaki Disease: a scientific statement for health professionals from the American Heart Association. Circulation. 2017;135(17):e927-99. https://doi.org/10.1161/ CIR.00000000000000484

20. Lazzaroni MG, Piantoni S, Masneri S, Garrafa E, Martini G, Tincani A, et al. Coagulation dysfunction in COVID-19: the interplay between inflammation, viral infection and the coagulation system. Blood Rev. 2021;46:100745. https://doi.org/10.1016/j.blre.2020.100745.

21. Simon Junior H, Sakano TMS, Rodrigues RM, Eisencraft AP, Carvalho VEL, Schvartsman C, et al. Multisystem inflammatory syndrome associated with COVID-19 from the pediatric emergency physician's point of view. J Pediatr. 2021;97(2):140-59. https://doi.org/10.1016/j.jped.2020.08.004.

22. Ranucci M, Ballotta A, Di Dedda U, Bayshnikova E, Dei Poli M, Resta M, et al. The procoagulant pattern of patients with COVID-19 acute respiratory distress syndrome. J Thromb Haemost. 2020;18(7):1747-51. https://doi.org/1 $0.1111 /$ jth. 14854 .

23. Consiglio CR, Cotugno N, Sardh F, Pou C, Amodio D, Rodriguez L, et al. The immunology of multisystem inflammatory syndrome in children with COVID-19. Cell. 2020;183(4):968-81 e967. https://doi.org/10.1016/j.cell.2020. 09.016.

24. Ramos-Casals M, Brito-Zeron P, Mariette X. Systemic and organ-specific immune-related manifestations of COVID-19. Nat Rev Rheumatol. 2021;17(6): 315-32. https://doi.org/10.1038/s41584-021-00608-z.

25. Connors JM, Levy JH. COVID-19 and its implications for thrombosis and anticoagulation. Blood. 2020;135(23):2033-40. https://doi.org/10.1182/ blood.2020006000.

26. Godfred-Cato S, Bryant B, Leung J, Oster ME, Conklin L, Abrams J, et al. COVID-19-associated multisystem inflammatory syndrome in children United States, march-July 2020. MMWR Morb Mortal Wkly Rep. 2020;69(32): 1074-80. https://doi.org/10.15585/mmwr.mm6932e2.

27. Yock-Corrales A, Lenzi J, Ulloa-Gutiérrez R, Gómez-Vargas J, Yassef AO, Aida JAR, Aguila OD, Arteaga-Menchaca E, Campos F, Uribe F et al: Antibiotic prescriptions in children with COVID-19 and Multisystem Inflammatory Syndrome: a multinational experience in 990 cases from Latin America. medRxiv 2020

28. Harwood R, Allin B, Jones CE, Whittaker E, Ramnarayan P, Ramanan AV, et al. A national consensus management pathway for paediatric inflammatory multisystem syndrome temporally associated with COVID-19 (PIMS-TS): results of a national Delphi process. Lancet Child Adolesc Health. 2021;5(2): 133-41. https://doi.org/10.1016/S2352-4642(20)30304-7.

29. Toubiana J, Poirault C, Corsia A, Bajolle F, Fourgeaud J, Angoulvant F, et al. Kawasaki-like multisystem inflammatory syndrome in children during the covid-19 pandemic in Paris, France: prospective observational study. BMJ. 2020:369:m2094.

\section{Publisher's Note}

Springer Nature remains neutral with regard to jurisdictional claims in published maps and institutional affiliations.

Ready to submit your research? Choose BMC and benefit from:

- fast, convenient online submission

- thorough peer review by experienced researchers in your field

- rapid publication on acceptance

- support for research data, including large and complex data types

- gold Open Access which fosters wider collaboration and increased citations

- maximum visibility for your research: over $100 \mathrm{M}$ website views per year

At $\mathrm{BMC}$, research is always in progress.

Learn more biomedcentral.com/submissions 